\title{
RAZÃO COMUNICATIVA E TÉCNICAS DE COMUNICAÇÃO E INFORMAÇÃO EM REDE
}

Flávio Beno Siebeneichler

\begin{abstract}
Resumo
O trabalho pretende demonstrar que a teoria da racionalidade comunicativa, desenvolvida por Jürgen Habermas, permite um posicionamento, a um só tempo, crítico e positivo, quanto às redes digitais. Porquanto seu desempenho não é apenas crítico no sentido de uma negação, mas principalmente criativo e dinâmico, visto que oferece o modelo de um procedimento discursivo - público e democrático - que permite avaliar pretensões de validade das redes digitais.
\end{abstract}

Palavras-chave: Razão Comunicativa; Razão Instrumental; Técnicas de Informação; Ideologia; Pesquisa Interdisciplinar.

\begin{abstract}
The paper intends to demonstrate that the theory of communicative rationality, developed by Jürgen Habermas, allows a position, at the same time, critical and positive, regarding digital networks. Because its performance is not only critical in the sense of a negation, but mainly creative and dynamic, since it offers the model of a discursive procedure - public and democratic - that allows evaluating validity claims of the digital networks.
\end{abstract}

Keyword: Communicative Reason; Instrumental Reason; Information Techniques; Information Techniques; Interdisciplinary Research.

\section{PREÂMBULOS.}

\subsection{SOBRE A TEORIA HABERMASIANA EM GERAL.}

A teoria habermasiana rompe dialeticamente a relação com a filosofia tradicional configurando-se como pensamento posplatônico, poskantiano e posmetafísico. Ela compartilha com Niklas Luhmann e outros teóricos contemporâneos, especialmente os que trabalham numa linha pragmática, hermenêutica e analítica, a ideia de que não podemos mais pressupor a existência de algo sublime, ideal ou superior que pudesse servir como ponto de referência de nossas investigações. Isso deriva do fato de que os seres humanos são finitos e contingentes, 
aliás, duplamente contingentes. Além disso, eles se encontram previamente e desde sempre imersos em um mundo da vida social que é profano, complexo e intransparente, estruturandose e concretizando-se mediante linguagem. Por isso, eles são extremamente vulneráveis.

Ora, uma destranscendentalização do sujeito cognoscente (HABERMAS, 2005), decorrente da perspectiva pós-platônica, convence Habermas de que a autoconsciência de um sujeito - a qual configurava o pólo principal do paradigma da filosofia moderna, onde era o centro gerador de sentido - não pode constituir-se a si mesma nem ser tida como um fenômeno único e isolado. Porquanto o espírito subjetivo adquire, por assim dizer, conteúdo e estrutura a partir de uma ancoragem no espírito objetivo formado por relações intersubjetivas que se estabelecem por uma comunicação entre sujeitos que, por natureza, são seres que se socializam em determinados contextos e dependem dessa socialização para se tornarem eles mesmos, seres autônomos e individuais (HABERMAS, 2005).

Por conseguinte, na linha desta interpretação intersubjetivista, a consciência particular de um sujeito jamais pode ser considerada, a rigor, privada, já que ela, de fato e até mesmo nos movimentos mais recônditos, alimenta-se de fluxos de uma rede cultural de informações, valores e pensamentos públicos expressos simbolicamente por linguagem e compartilhados intersubjetivamente. Tal pressuposto, que constitui sem dúvida alguma, uma das molas mestras do pensamento habermasiano transparece, inequivocamente, na seguinte passagem: "Jamais consegui aceitar a ideia de que a autoconsciência constitui por si mesma um fenômeno originário [...] somente nos tornamos conscientes de nós mesmos nos olhares que um 'outro' dirige a nós” (HABERMAS, 2005).

Entretanto, Habermas, não se limita a tecer considerações poéticas sobre esse tema fascinante da constituição social e política do sujeito humano. Ao invés disso, ele se dedica ao trabalho multifacetado, longo e complexo de soletrar sistematicamente essa ideia em uma teoria crítica da sociedade, em uma teoria moral e em uma teoria política. E levado por tal intuito, ele

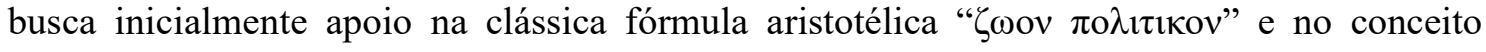
"animal sociale et politicum", de Tomás de Aquino (HABERMAS, 1972), que amplia e radicaliza a ideia aristotélica. Habermas traduz os dois conceitos, o de Aristóteles e o de Tomás de Aquino, para a seguinte asserção: o homem é um animal que vive em um espaço público. Ou seja, ele é um ser vivo que consegue desenvolver as competências que o transformam em uma pessoa "graças à sua inserção originária em uma rede pública de relações sociais" (HABERMAS, 2005). Tal ideia é reforçada, ainda mais, por estoutra: "Nós, homens, aprendemos uns dos outros. E isso somente é possível no interior de um espaço público capaz de fornecer estímulos culturais" (HABERMAS, 2005).

LOGEION: Filosofia da informação, Rio de Janeiro, v. 5, 2018, Edição Especial, p.49-66 
É interessante constatar que a escolha do paradigma da constituição intersubjetiva do espírito humano permitiu a Habermas configurar uma teoria do agir comunicativo com teor normativo, a qual é obtida, não da ideia de uma constituição ontológica do ente ou da subjetividade, tal como é proposto pela fenomenologia husserliana (HABERMAS, 2005). Mas de uma prática de argumentação ou discurso que se estabelece entre sujeitos interessados em entendimento público sobre algo que se faz presente no seu mundo cotidiano. ${ }^{1}$

\subsection{CONSIDERAÇÕES SOBRE O POSSÍVEL DESEMPENHO DA RAZÃO COMUNICATIVA NO MUNDO DAS INFORMAÇÕES EM REDE.}

1.3. EM PRIMEIRO LUGAR, CONVÉM LEMBRAR QUE A PRESENTE COMUNICAÇÃO PRETENDE AVERIGUAR SE, E ATÉ QUE PONTO, A TEORIA DA RAZÃO COMUNICATIVA TEM ALGUMA SERVENTIA PARA A ORIENTAÇÃO DO HOMEM NA SOCIEDADE ATUAL QUE SE ENCONTRA EM PROCESSO DE GLOBALIZAÇÃO E QUE SE ORGANIZA MEDIANTE TECNOLOGIAS DE INFORMAÇÃO E COMUNICAÇÃO.

Trata-se de uma sociedade onde predominam, de um lado, as técnicas desenvolvidas a partir das ciências da informática que tratam da informação e da comunicação por meio de máquinas, computadores, técnicas eletrônicas, digitais e outros meios automáticos. Isso faz com que nesta sociedade adquira forma cada vez mais nítida uma esfera ou ambiente digital que o escritor canadense William Gibson caracterizou, em 1984, como ciberespaço. Neste espaço as informações são transferidas de um ponto a outro em uma rede digital multirramificada que não necessita da mais presença física do homem: porquanto aqui tudo acontece mediante impulsos eletrônicos e "imagens anônimas", impessoais.

Ora, um dos principais problemas relacionados ao ciberespaço consiste na acessibilidade das informações, isto é, na possibilidade técnica de transmissão de qualquer informação, em qualquer lugar, em qualquer momento, com qualidade técnica, mobilidade, interatividade. E na possibilidade de acesso ilimitado a elas.

\footnotetext{
${ }^{1} \mathrm{O}$ seguinte trecho pode elucidar este tema: “A teoria discursiva procura obter um conteúdo normativo da prática de argumentação, da qual nos sentimos dependentes sempre que nos encontramos em uma situação insegura - não apenas enquanto filósofos ou cientistas, mas também quando, em nossa prática comunicativa cotidiana, a quebra de rotinas nos obriga a parar um momento e a refletir, a fim de nos certificarmos reflexivamente acerca de expectativas justificadas. Por conseguinte, o ponto de partida é dado pelo conteúdo normativo de pressuposições pragmáticas inevitáveis, nas quais participantes da argumentação tem de se apoiar implicitamente quando levados pela pretensão de resgatar pretensões de validade controvertidas - decidem-se a tomar parte em uma busca cooperativa da verdade a qual assume a forma de uma disputa pelos melhores argumentos". (Cf. HABERMAS, 2005, p. 88-89).
}

LOGEION: Filosofia da informação, Rio de Janeiro, v. 5, 2018, Edição Especial, p.49-66 
Essa nova realidade do ciberespaço afeta, sem dúvida alguma, não apenas a vida, o trabalho, o lazer dos indivíduos em particular, mas também a comunicação entre as pessoas, a educação, a cultura, a política, numa palavra, a vida da sociedade em geral. Isso por duas razões. Primeira razão: o acesso público às informações em rede pode contribuir para melhorar a qualidade de vida das pessoas em geral. Segunda razão: as tecnologias digitais permitem novos tipos de controle das informações por parte de quem possui o poder econômico, político ou técnico-científico.

\subsubsection{Em segundo lugar, nossa abordagem sobre o lado prático da razão comunicativa nos remete, inicialmente, a um problema mais amplo que preocupa a filosofia em geral, desde a sua origem no mundo helênico.}

Trata-se do velho problema, ainda não bem solucionado, que se coloca a partir do momento em que a própria filosofia que se autodefine como discurso essencialmente analítico e formal sobre a verdade, procura certificar-se sobre a sua serventia para a vida humana concreta. Esse problema é tratado em geral sob a forma de uma discussão sobre as possíveis relações entre teoria e prática ou práxis. A tradição nos apresenta muitas respostas a esse problema central, algumas delas conflitantes. Sobressaem nesse contexto respostas de Platão, Aristóteles, Hegel e da Teoria Crítica, as quais merecem uma rápida menção.

A resposta platônica.

Segundo Platão, nada é mais prático do que a própria teoria, a qual consiste, segundo ele, na imersão em uma contemplação do cosmo mediante a qual o homem pode chegar a uma conversão da alma ou do espírito. Ao ascender cada vez mais alto, rumo à contemplação das ideias puras e verdadeiras, a alma se purifica de interesses e paixões rasteiras, liberta-se da matéria e da prisão do corpo. Ora, parece claro que, nesta linha de raciocínio a vida teórica ou contemplativa tem a precedência sobre a vida prática cotidiana envolta em problemas técnicos, pragmáticos, morais, políticos, pedagógicos, etc.

Ora, uma filosofia que assumisse tal perspectiva platônica - como é o caso da filosofia heideggeriana - pouco teria para dizer sobre as questões ligadas às técnicas de informação e comunicação, especialmente as oriundas do ciberespaço contemporâneo.

A resposta de Aristóteles. 
É bem verdade que Aristóteles, apesar de sua pertença ao mundo grego e, inclusive, apesar de sua condição de discípulo de Platão - o melhor de todos, inclusive, - encontrou uma resposta diferente para a questão envolvendo as possibilidades de desempenho prático da filosofia: Para ele, uma filosofia pode sim - ao contrário do que pensava seu mestre Platão adquirir importância para a prática cotidiana a partir do momento em que ela mesma assumir a forma de uma filosofia prática especializada em questões éticas e políticas que se referem a uma conduta inteligente de vida do indivíduo, seja no seu lar, seja na polis. Porquanto, segundo ele, nesta forma ela tem condições de oferecer conteúdos e modelos de uma vida racional, sábia e prudente, bem-sucedida.

A resposta de Hegel.

No século XIX, portanto, mais de dois milênios mais tarde, Hegel segue, de um lado, as pegadas de Platão e Aristóteles. Todavia, ele imagina que o desempenho prático da filosofia pode ir ainda mais longe, porquanto, segundo ele, a principal função prática da filosofia consiste no fato de que ela é capaz de antecipar - em pensamentos - a forma de uma convivência social justa, isto é, ela pode oferecer a possibilidade de uma concretização da razão na história. Dito de outra forma: a filosofia pode trabalhar amparada na hipótese de que é possível antecipar - mediante projeção de uma totalidade racional absoluta - normas racionais para um posicionamento "humano" do homem em meio a uma realidade irracional.

A resposta da Teoria Crítica (Adorno, Horkheimer, Marx, Lukacs, Marcuse).

Marx assume, de um lado, o conteúdo racional contido na proposta da filosofia prática hegeliana. Rejeita, no entanto, a configuração idealista dessa proposta e simplesmente inverte a relação clássica estabelecida entre teoria e prática. A partir daí a primazia vai ser dada unicamente à prática, não mais à teoria. E o que é mais importante ainda: a teoria é, por assim dizer, retirada da totalidade de um espírito absoluto e inserida em um todo social vital cuja base é material (HABERMAS, 1999).

Nesse plano, a teoria pode assumir dois sentidos distintos: o de consciência falsa e o de crítica. Porquanto ela é tida como capaz de descobrir sua dependência de um contexto objetivo ao qual estava ligada sem se dar conta.

Não é possível desenvolver aqui esse tema fascinante que quase sempre retorna nas discussões sobre o desempenho, a utilidade ou inutilidade - ou até a futilidade - da filosofia. É possível constatar isso nos trabalhos dos filósofos que tentam compreender a praticidade da filosofia em termos de uma teoria crítica da sociedade ou da economia capitalista seguindo as LOGEION: Filosofia da informação, Rio de Janeiro, v. 5, 2018, Edição Especial, p.49-66 
pegadas de Marx, Lukács, Horkheimer, Adorno ou Herbert Marcuse. Ora, nesta linha de pensamento o desempenho prático da filosofia consiste em uma crítica radical e contínua cujo desempenho é sempre indireto: configura-se como detecção e negação de caminhos falsos, distorções, paradoxos, unilateralidades, desvios (Dialética negativa) em nome de uma praxis humana totalmente diferente, tida como melhor, mais justa ou mais racional, emancipada.

\subsubsection{Em terceiro lugar, convém lembrar que a teoria da razão comunicativa, que pretendemos analisar, mantem uma relação com a Teoria Crítica.}

A teoria da razão comunicativa ainda não foi concluída. No entanto, é certo que ela guarda, desde o seu início, uma relação dialética com a Teoria Crítica. E esta relação existe não somente pelo fato de a Teoria Crítica ter sido o berço da teoria do agir comunicativo, mas também e principalmente porque esta mantém um dos traços mais característicos daquela, a saber, a amarração intrínseca, interdisciplinar, entre a filosofia e as ciências.

Por isso, julgo necessário, para uma correta compreensão da racionalidade comunicativa, reconstruir em um primeiro momento - mesmo que sumariamente - o debate de Habermas com Herbert Marcuse sobre a possível influência ideológica da ciência e das técnicas em geral - especialmente as da mídia - na prática da vida humana. Esse debate constitui, inclusive, uma senda importante, um início da elaboração da Teoria do Agir Comunicativo. Espero, por este caminho, esclarecer de uma forma mais natural e adequada os conceitos, entrelaçados, de racionalidade, racionalização, agir teleológico/instrumental, agir comunicativo, razão instrumental e razão comunicativa.

E nesse procedimento procuro evitar o caminho que muitos pretensos habermasianos seguem e que consiste em tomar diretamente a razão comunicativa como um princípio último ou premissa que permite interpretações variadas e indiscriminadas sobre toda e qualquer questão referente ao mundo da vida. Eles esquecem, ou melhor, desconhecem a admoestação de Habermas (1985), explicitada no primeiro volume de TAC (Teoria da Ação Comunicativa), segundo a qual esse conceito ou quase-intuição constitui algo não concluído e que deve ser alvo de um contínuo esforço teórico que requer a cooperação crítica não somente de teóricos da área da filosofia, mas também das ciências, especialmente das ciências sociais e humanas. Esquecem ou não sabem que os contornos da teoria do agir comunicativo e da razão comunicativa começam - curiosamente - a se tornar mais nítidos no âmbito de um debate sobre a correta interpretação filosófica da ciência e das tecnologias modernas. E nesse ponto sobressai 
o debate de Habermas com Herbert Marcuse sobre a correta interpretação da ciência e das técnicas contemporâneas.

\section{PRIMEIROS CONTORNOS DA RAZÃO COMUNICATIVA NA CRÍTICA DE HABERMAS AO CONCEITO DE CIÊNCIA E TÉCNICA EM MARCUSE.}

\subsection{A TESE DE MARCUSE SOBRE O CARÁTER IDEOLÓGICO DA CIÊNCIA E DA TÉCNICA.}

A argumentação marcusiana pode ser sintetizada nos seguintes pontos: A grande novidade histórica que irrompe com o surgimento da era da ciência e da técnica consiste no fato de que as forças produtivas assumem uma nova relação com suas condições de produção. Deixam de lado sua função esclarecedora e emancipatória para se transformarem na base de legitimação do poder político (HABERMAS, 1969, p. 52). Como consequência disso, se pereniza e se amplia, segundo Marcuse, a dominação. Ela não resulta simplesmente do uso indiscriminado e reiterado dos mais diferentes tipos de tecnologias. Mas é consequência da própria natureza da técnica, a qual passa a oferecer, enquanto técnica, uma base de legitimação para o poder político.

Desta forma, ela consegue racionalizar uma escravidão do homem porquanto comprova cientificamente a impossibilidade técnica de ele determinar sua vida por conta própria. O curioso é que tal "não liberdade" aparece como algo racionalmente justificável, por conseguinte, "não irracional", visto que a submissão total e irrestrita ao aparato tecnológico amplia o conforto da vida cotidiana e a produtividade do trabalho.

De fato, porém, uma sociedade tecnológica avançada impede, no fundo, a autonomia de pensamento, elimina o direito de se opor, de dizer "não". Porque ela cria necessidades falsas, as quais integram o indivíduo ao sistema de produção e consumo. Tal estado de coisas culmina em uma sociedade totalmente irracional inserida em um universo unidimensional, instrumental e totalitário (totalmente administrada, diria Adorno) que abriga seres que são racionalmente não-livres, privados de suas dimensões essenciais, numa palavra, homens unidimensionais dominados pela tecnologia e pela máquina (MARCUSE, 1967). E tal espécie de homem conformista e consumista não consegue nem se posicionar quanto à sua felicidade: ele é feliz somente quando a mídia ou o sistema lhe sugerem que é.

Para enfrentar os desafios resultantes dessa situação do homem unidimensional Marcuse apresenta uma nova consciência crítica capaz de formular uma grande recusa 
revolucionária, especialmente da juventude, em nome da liberdade, da beleza, da felicidade e da paz.

Esta grande recusa permitiria, segundo ele, a concepção de uma nova ciência e de uma nova técnica de domínio da natureza, distintas das atuais, capazes de propiciar um novo caminho libertador. Permitiria, além disso, a concepção de uma arte revolucionária - não conformista - capaz de expressar de modo autêntico as características de um novo homem pluridimensional.

\subsection{POSIÇÃO DE HABERMAS.}

\subsubsection{Crítica a Marcuse.}

Segundo Habermas, Marcuse teve o grande mérito de ter sido o primeiro pensador a focalizar o conteúdo político da razão técnica e o primeiro a tomar esse conteúdo como ponto de partida para uma análise global da sociedade capitalista tardia dominada pelos meios de comunicação de massa (HABERMAS, 1969). Além disso, ele encontrou a chave para uma análise das tendências fundamentais da nova constelação em que se encontra essa sociedade.

Não obstante isso, Habermas discorda de Marcuse em um ponto importante: não é possível conceber uma nova ciência e uma nova técnica já que não podemos considerar a racionalidade da ciência e da técnica como sendo apenas o projeto particular de uma determinada época histórica, no caso, a modernidade liberal (HABERMAS, 1969). Ou seja, não parece plausível, segundo Habermas, substituir nossa ciência e nossa técnica por outro elemento, qualitativamente melhor. Isso porque ambas constituem, segundo ele, um projeto da humanidade como um todo.

Por esta razão, Habermas pensa que a ideologia atual não deve ser buscada na essência da ciência e da técnica, mas em uma peculiar consciência tecnocrática típica de uma visão encurtada da racionalidade humana que inclui nesta categoria apenas atividades teleológicas, isto é, comportamentos ou escolhas que são racionais em ordem a fins ou objetivos propostos.

\subsubsection{Distinção entre trabalho e interação, entre razão instrumental e comunicativa.}


Habermas considera que a racionalidade teleológica, instrumental, constitui apenas um dos aspectos essenciais da racionalidade humana, que é mais ampla e multifacetada. Por isso ele reformula o conceito de racionalidade, de Weber, apoiado em dois conceitos que ele desenvolve a partir de Hegel. Trata-se dos conceitos de trabalho e interação que, em conjunto com a linguagem, caracterizam a história da espécie humana como um todo (HABERMAS, 1969).

O "trabalho" é interpretado como "agir teleológico, instrumental que pode referirse a uma escolha racional, a um comportamento racional ou a uma combinação de ambos. É importante observar que, enquanto agir instrumental, o trabalho segue regras técnicas que dependem de um saber empírico. Implica, pois, eventos observáveis (físicos, sociais, etc.) e prognósticos. E enquanto atitude de escolha racional orienta-se por estratégias que dependem de um saber analítico, isto é, implica deduções de sistemas de valores, preferências e máximas técnicas que podem ser corretas ou incorretas.

Ao passo que a "interação entre sujeitos" ou "agir comunicativo" caracteriza uma atividade racional e intersubjetiva mediada por símbolos e pela linguagem. Além disso, ela se orienta - necessariamente - por normas que definem expectativas recíprocas de comportamento, as quais estão em vigor ou são tidas como válidas. Estas normas têm de ser reconhecidas por pelo menos dois sujeitos agentes (HABERMAS, 1969).

O quadro elaborado a seguir pretende favorecer a compreensão dessa questão mediante contraposição esquemática dessas duas visões de racionalidade:

Quadro - 1: Das concepções de racionalidade:

\begin{tabular}{|l|l|l|l|}
\hline $\begin{array}{l}\text { Paradigma } \\
\text { weberiano }\end{array}$ & Ego $\rightarrow$ & $\begin{array}{l}\text { conhece } \\
\text { representa } \\
\text { manipula } \\
\text { (mediante técnicas) }\end{array}$ & $\begin{array}{l}\text { objetos } \\
\text { eventos } \\
\text { pessoas }\end{array}$ \\
\hline $\begin{array}{l}\text { Paradigma } \\
\text { habermasiano }\end{array}$ & Ego $\rightarrow$ & $\begin{array}{l}\text { comunica-se } \\
\text { com Alter }\end{array}$ & $\begin{array}{l}\text { a fim de chegar a um entendimento sobre } \\
\text { o significado do conhecimento e da } \\
\text { manipulação de objetos }\end{array}$ \\
Ego $\rightarrow$ & comunica-se com Alter & $\begin{array}{l}\text { a fim de utilizá-lo como meio para a } \\
\text { obtenção de outra finalidade }\end{array}$ \\
\hline
\end{tabular}

Fonte: $\mathrm{O}$ autor

Esta distinção entre razão técnica, instrumental, e razão interacional ou comunicativa é de fundamental importância para a compreensão do arcabouço teórico de Habermas. Já que ela permite não somente reinterpretar a passagem de uma "sociedade tradicional" - onde predomina uma base de legitimação inquestionável propiciada por instituições e tradições que obedecem a contextos de interação - para uma sociedade pósLOGEION: Filosofia da informação, Rio de Janeiro, v. 5, 2018, Edição Especial, p.49-66 
tradicional, onde subsistemas do agir instrumental e a inovação tecnológica assumem o lugar e as funções das antigas tradições (HABERMAS, 1969).

A partir daqui é possível distinguir dois tipos de sistemas sociais: de um lado, o quadro institucional de uma sociedade ou mundo da vida sociocultural. De outro lado, subsistemas de agir teleológico/instrumental, os quais se encontram "embutidos" em um mundo da vida sociocultural (HABERMAS, 1969).

Em segundo lugar, a distinção entre razão instrumental e comunicativa permite não somente superar o paradoxo decorrente da tese marcusiana sobre o caráter ideológico da ciência e da técnica, mas também descobrir que a nova ideologia reside muito mais em uma consciência tecnocrática. Esta é capaz de camuflar e, inclusive, eliminar a diferença entre interação intersubjetiva e atividades de cunho teleológico ou instrumental (HABERMAS, 1969).

Tal consciência tecnocrática não tem mais a forma característica das velhas ideologias (HABERMAS, 1969).

Ela é, aparentemente, menos ideológica do que todas as ideologias anteriores porquanto não possui a "força opaca de uma obnubilação de interesses ou de uma consciência falsa. Ela é, muito mais do que isso, "ideologia vítrea", transparente, capaz de transformar a ciência em um fetiche. E nesse sentido ela é mais eficaz e mais abrangente até do que as ideologias que a precederam já que, ao camuflar questões práticas que têm a ver com interação entre sujeitos, legitima não somente o interesse parcial ou a necessidade de emancipação de certas classes bem determinadas, mas o interesse emancipatório geral da espécie humana enquanto tal (HABERMAS, 1969).

Tudo indica, pois, que o debate com Marcuse instigou Habermas a traçar uma diferença essencial entre razão técnica, instrumental (teleológica) e razão inserida em linguagem e interação (razão comunicativa). E lhe permitiu também estabelecer - contra Weber - a existência de dois tipos de racionalização:

- No nível dos subsistemas do agir teleológico-instrumental o progresso técnico (a racionalização) leva a uma reorganização de sistemas e instituições sociais.

- Ao passo que no nível da moldura institucional a racionalização somente pode acontecer no contexto ou no médium de uma interação linguística, isto é, mediante franqueio da comunicação por linguagem, ou, melhor ainda, mediante uma discussão pública ilimitada e isenta de coação sobre princípios, normas e consequências de subsistemas que evoluem (HABERMAS, 1969). 
Chegamos assim à terceira parte onde tentarei delinear sumariamente o contorno da racionalidade comunicativa lançando mão dos elementos contidos em uma teoria explícita e sistemática do agir comunicativo, construída com elementos de uma pragmática formal.

\section{A RAZÃO COMUNICATIVA NA TEORIA DO AGIR COMUNICATIVO.}

\subsection{PROBLEMA INICIAL}

O primeiro problema que se apresenta nesse contexto tem a ver com o modo fundamentação da validade geral do conceito razão comunicativa. Como é possível tal fundamentação, uma vez que estamos impedidos de lançar mão das garantias oferecidas pela tradição filosófica platônica, que Habermas rejeita? (HABERMAS, 1985).

Esse problema faz sentido, já que Habermas (1985), "utiliza o conceito de razão comunicativa sem enrubescer" e não pretende, ao mesmo tempo, cair nas armadilhas de um fundamentalismo. Ele sabe que a filosofia não tem mais condições de se apresentar como detentora de um saber abrangente e referido à totalidade do mundo, da natureza, da história ou da sociedade. Isso significa que ela não é mais autossuficiente, sendo, por isso, obrigada a assumir uma nova relação de cooperação com as ciências, especialmente as ciências sociais e humanas (HABERMAS, 1985).

Por essa razão, ao elaborar a teoria do agir comunicativo ele obedece a dois interesses distintos: o de um filósofo que analisa conceitos; e o de um sociólogo que se pergunta acerca da utilidade prática das análises de conceitos levada a cabo pelo filósofo. Isso obriga a adotar um dualismo metódico. Ele justifica tal procedimento amparado num pressuposto hegeliano e pragmático, segundo o qual, a formação e a fundamentação de conceitos andam sempre junto com a resposta a questões substanciais e práticas (HABERMAS, 1985).

\subsection{A RAZÃO COMUNICATIVA PODE SER ACESSADA A PARTIR DO CONCEITO "AGIR COMUNICATIVO.}

Habermas, ele mesmo, afirma que para compreender o conceito de razão comunicativa que ele introduz de modo intuitivo basta clarificar as características formais do agir comunicativo que inevitavelmente se orienta por entendimento, já que a razão comunicativa "habita no interior do agir comunicativo" (HABERMAS, 1985). Por isso, convem lembrar, inicialmente, os tipos de agir destacados por ele. 
Ora, a partir da discussão das teses de Marcuse e Max Weber, fica claro que Habermas distingue três tipos fundamentais de agir ou ação: a) Agir teleológico ou instrumental. Nesta linha de atividade um agente realiza um fim ou provoca um estado de coisas desejado à proporção que escolhe meios adequados e os aplica. b) Agir estratégico mediante o qual o agente insere no cálculo do sucesso de sua ação a expectativa das decisões e atitudes de outro agente. c) Agir comunicativo que é a forma primordial e paradigmática do agir humano. Este tipo de atividade se constitui na forma de uma interação entre dois sujeitos dotados da faculdade de falar e agir, os quais assumem uma relação interpessoal a fim de chegarem a um entendimento sobre determinada situação de sua ação intersubjetiva ou a fim de coordenarem consensualmente seus planos de ação (HABERMAS, 1985).

Quadro - 2: Dos tipos de ações humanas, segundo Habermas.

\begin{tabular}{|l|l|}
\hline & $\begin{array}{l}\text { Agir instrumental: um agente } \\
\text { procura concretizar determinado } \\
\text { objetivo lançando mão de } \\
\text { certos meios. }\end{array}$ \\
$\begin{array}{l}\text { Um agente se propõe a realização de } \\
\text { formas: }\end{array}$ & $\begin{array}{l}\text { Agir estratégico: o agente } \\
\text { insere no cálculo do sucesso } \\
\text { de sua ação as possíveis } \\
\text { reações de outro agente. }\end{array}$ \\
$\rightarrow \begin{array}{l}\text { Agir comunicativo: o agente } \\
\text { procura entender-se com outro } \\
\text { agente sobre algo no mundo. }\end{array}$ \\
\end{tabular}

Fonte: $\mathrm{O}$ autor

Podemos constatar, por conseguinte, que é comum a essas três formas de agir uma estrutura teleológica, finalista. O que muda é apenas a natureza do fim ou telos: No agir instrumental o fim consiste na obtenção de conhecimentos ou na possibilidade de um controle técnico; ao passo que o fim do agir comunicativo reside no próprio entendimento e no possível acordo intersubjetivo quanto a pretensões de validade racional. Ora, o entendimento que é essencial para a prática comunicativa cotidiana compreende dois aspectos distintos que é necessário levar em conta: ele constitui, de um lado, um processo cognitivo. E de outro, um processo de união entre sujeitos capazes de fala e que, devido a essa competência, sabe distinguir intuitivamente quando as suas ações têm por objetivo influenciar estrategicamente outras pessoas e quando o seu objetivo consiste unicamente em se entender com elas ou em chegar a um acordo sobre pretensões de validade questionadas (HABERMAS, 1985).

Por essa razão, a teoria do agir comunicativo coloca em jogo um processo discursivo de entendimento que visa um consenso apoiado em razões ou argumentos. Por isso, tal 
entendimento não pode ser imposto por nenhuma das partes envolvidas. Nenhum acordo sobre pretensões de validade pode ser extorquido por via instrumental, mediante intervenção direta na situação da ação, nem por via estratégica, mediante intervenção calculada nas decisões da outra parte (HABERMAS, 1985).

Nesta perspectiva, o ato de fala de um ator somente é bem sucedido quando outro ator aceitar a oferta ou pretensão de validade nele contida. Dito de outra forma: o êxito de um ato de fala comunicativo depende de um acordo sobre a razoabilidade das pretensões de validade nele exteriorizadas. Isso quer dizer que, tanto o falante que exterioriza uma pretensão de validade acerca de algo no mundo como o ouvinte que a aceita ou recusa, apoiam suas decisões em argumentos que podem ser aceitos ou rejeitados no decorrer de um processo discursivo orientado por entendimento. ${ }^{2}$

Convém destacar, além do mais, o fato de que a razão comunicativa esta inscrita no agir comunicativo na forma de um leque de pretensões de validade questionáveis e resgatáveis mediante argumentos. Isso faz com que a vida cotidiana dos indivíduos e dos cidadãos atualmente envolvidos pela informação e a comunicação em rede - esteja submetida, incessantemente, a novos problemas e a novos processos de aprendizagem (HABERMAS, 1988).

Além disso, a inserção da razão comunicativa em atividades comunicativas impõe certas idealizações que permitem a formulação de uma crítica às condições da atual sociedade dominada pelo ciberespaço. A seguinte citação, extraída da obra já citada, Pensamento posmetafísico, pode comprovar tal afirmação:

A ideia do resgate de pretensões de validade questionáveis pressupõe idealizações que - descidas do céu transcendental para o solo do mundo da vida - desenvolvem sua eficácia no médium da linguagem natural. Nelas se manifesta a força de resistência de uma razão comunicativa que opera de modo astuto contra as deformações cognitivo-instrumentais de formas de vida modernizadas de modo seletivo (HABERMAS, 1988).

Podemos, pois, concluir que a razão comunicativa - pelo fato de transparecer no agir comunicativo e na troca de argumentos sobre o que experimentamos no mundo e sobre o que pensamos em geral - é pública. Por conseguinte, não pode ser tida na conta de uma

\footnotetext{
2 Pressupostos de uma prática de argumentação na qual se busca entendimento:

- A existência de uma esfera ou espaço público.

- Inclusão (ao menos virtual) de todos os afetados pela questão em pauta.

- Distribuição equitativa dos direitos de comunicação.

- Situação isenta de coações, isto é, uma situação na qual se admite apenas o melhor argumento cujo força é isenta de qualquer tipo de constrangimento.

- Sinceridade de todos os participantes. (Cf. HABERMAS, 1999).
}

LOGEION: Filosofia da informação, Rio de Janeiro, v. 5, 2018, Edição Especial, p.49-66 
inteligência que apenas conhece e calcula secretamente. Ela está interligada com os demais tipos da racionalidade humana, como pode ser depreendido do seguinte quadro que sintetiza as raízes da racionalidade comunicativa:

Quadro - 3: Das raízes, entrelaçadas, da racionalidade comunicativa.

\begin{tabular}{|l|c|l|}
\hline Ego & representa ou manipula objetos & Racionalidade epistêmica \\
\hline Ego & age & $\begin{array}{l}\text { Racionalidade teleológica ou } \\
\text { finalista (racional com respeito a fins) }\end{array}$ \\
\hline Ego & fala & $\begin{array}{l}\text { Racionalidade comunicativa. O objetivo da } \\
\text { fala é o entendimento com Alter }\end{array}$ \\
\hline
\end{tabular}

Fonte: Elaborado a partir de Habermas, 1997.

Por conseguinte, a perspectiva aberta por esta racionalidade complexa e entrelaçada não é intuitiva, mas discursiva. Como consequência disso, quando pretendemos saber se um enunciado é verdadeiro ou se uma determinada forma de agir é correta temos de percorrer sempre - um caminho sulcado de argumentos e contra-argumentos (WINGERT; GÜNTHER, 2001). E nem sempre chegamos a ter certeza. Neste ponto Habermas compartilha uma convicção de Kant, segundo a qual, nós não temos à disposição nenhum tipo de acesso imediato ou intuitivo a qualquer forma de verdade, teórica ou prática. Por isso temos de lançar mão de procedimentos discursivos. E isso impede que a verdade seja considerada propriedade privada de alguém, de um filósofo, cientista ou teólogo.

Neste ponto a razão comunicativa revela sua principal serventia para a atual sociedade que se abre de forma global e se liga por redes tecnológicas de comunicação e informação. Porquanto ela pode ser caracterizada como a capacidade humana de criar argumentos em discursos que podem desenvolver-se em qualquer tipo de espaços públicos e democráticos da sociedade. Dadas essas características, ela permite não somente superar visões unilaterais da ciência, da técnica e da informação, isto é, as visões que vislumbram nelas apenas racionalidade instrumental reificadora ou coisificadora, mas também criar perspectivas de um fecundo trabalho de pesquisa e de aprendizagem interdisciplinar. Porque a busca da verdade por este caminho implica necessariamente pacientes e metódicos esforços discursivos que envolvem cooperação entre várias disciplinas. 


\section{RAZÃO COMUNICATIVA E INFORMAÇÃO EM REDE.}

As considerações anteriores nos conduziram até o limiar de uma racionalidade comunicativa que se configura de modo plural e descentrado, cuja unidade é formal e procedimental. Ela transparece no agir comunicativo exercendo-se em práticas discursivas, públicas e democráticas, de pretensões de validade questionáveis.

Convém perguntar, agora: que tipo de desempenho tal conceito pode oferecer ao homem de hoje que é profundamente dependente de conhecimentos, tecnologias e informações que são transmitidas por uma imensa rede de redes mundiais de computadores ligados entre si?

No meu entender, os quatro itens seguintes têm a ver com um possível desempenho da razão comunicativa:

\subsection{RACIONALIDADE INSTRUMENTAL VERSUS RACIONALIDADE COMUNICATIVA.}

Convém salientar, em primeiro lugar, que a diferença entre racionalidade instrumental e comunicativa, introduzida quando da apresentação da tese de Marcuse sobre o caráter ideológico e reificador da ciência e da técnica, permite uma abordagem diferenciada e mais produtiva dos problemas gerados pelo novo mundo da informática. Aqui, talvez, os problemas já apontados por Marcuse retornam de forma mais aguda. A atenção para a diferença entre os dois tipos de racionalidade permite, ao menos, que nos mantenhamos em guarda contra as tentativas de ideologização do mundo da informática.

\subsection{A TEORIA DA RACIONALIDADE COMUNICATIVA REVELA UM NOVO CAMINHO PARA A FILOSOFIA E AS CIÊNCIAS.}

Em segundo lugar, penso que teoria da razão comunicativa mostra um novo caminho para a própria filosofia e para as ciências. Elas são conclamadas a dar contribuições em esferas públicas onde se discutem problemas atinentes ao mundo digital, um mundo fascinante, promissor e, ao mesmo tempo, repleto de riscos para a emancipação do homem.

A partir do momento em que a filosofia adota a perspectiva da racionalidade comunicativa, ela vai perder a sua ingenuidade no campo da prática e não vai mais poder centralizar o seu trabalho na formulação de admoestações apocalípticas ou moralistas contra os meios de comunicação em geral e contra o mundo digital em particular. Ela não vai mais poder 
assumir a posição que Niklas Luhmann ironicamente caracteriza como a de uma "coruja de Minerva que choraminga pelos cantos”.

Este novo caminho é certamente árduo porque leva a filosofia, desejosa de encontrar a verdade da informação em rede, a buscar cooperação estreita com as ciências e as técnicas.

Ora, a partir deste momento, ela não pode mais pressupor que existe uma instância superior mais sábia capaz de ensinar aos outros. Também não pode mais fazer de conta que existe alguém predestinado para carregar o destino da humanidade às suas costas. A sociedade compõe-se apenas de participantes muitos dos quais se encontram em um processo de busca sincera da verdade onde o que conta são os melhores argumentos. Mesmo que eles não tenham sido produzidos pela filosofia!

\subsection{UM EXEMPLO DE TRABALHO INTERDISCIPLINAR}

O sociólogo francês Michel Maffesoli pode ser citado como exemplo de um trabalho interdisciplinar e cooperativo, mesmo que ele não tome como guia explícito o conceito de razão comunicativa. Ele se dedica ao estudo dos problemas produzidos no campo atual da informação e da comunicação lançando mão de elementos teóricos extraídos da filosofia e da sociologia. Ele toma como ponto de partida o conceito de "vibrar", que Heidegger define como sendo característica de um "compreender" e o interpreta como um "comunicar" que, por seu turno, constitui um "vibrar com outro", isto é, uma interação. Apoiado nesse conceito, ele desenvolve uma crítica dirigida contra os intelectuais que não conseguem detectar nenhum laço social entre informação e comunicação (MAFFESOLI, 2003).

Para Maffesoli (2003), a informação possui um substrato ou potência social subterrânea. E tal substrato constitui um obstáculo à instrumentalização total da informação e da comunicação. Tal substrato comunicativo, isto é, o "vibrar com outros" transparece na mídia e nas redes digitais porquanto as pessoas não querem apenas informação, mas também se ver, se ouvir e participar. E esse desejo não é eliminado nem mesmo quando "sociedade de informação", a qual é incapaz de entender o sentido do relacionar-se com outros e o "vibrar", se esforça em fazer crer que o que interessa, acima de tudo, são os meios, os sistemas, os aparelhos, os programas e as técnicas de informação. Não a comunicação em si mesma ou o entendimento entre as pessoas.

Gostaria de retomar, no final destas considerações, uma ideia habermasiana sobre a comunicação por meio da mídia eletrônica e digital esboçada na obra intitulada Era das LOGEION: Filosofia da informação, Rio de Janeiro, v. 5, 2018, Edição Especial, p.49-66 
transições. Neste texto ele afirma que a comunicação digital desempenha uma função importante na sociedade atual que se encontra em transição para um mundo cada vez mais complexo e globalizado e interligado por redes de redes digitais. Nesse tipo de sociedade digital o público não está presente fisicamente, mas disperso. Isso não impede, porém, no entender de Habermas, que ele, em momentos fugidios do cotidiano, em círculos pequenos ou privados, se informe sobre todos os temas possíveis e dê suas contribuições através de meios de comunicação de massa, principalmente através do computador (HABERMAS, 2001). E isso torna possível a participação das pessoas na discussão de opiniões públicas e de pretensões de validade concorrentes. Mesmo que elas não participem sempre da articulação das opiniões. $\mathrm{O}$ que não impede que elas participem da avaliação dessas opiniões.

O que importa, acima de tudo, é que a comunicação não se rompa e a liberdade comunicativa, isto é, a liberdade de dizer "sim" ou "não" a opiniões e pretensões de validade exteriorizadas não sofra entraves. Por que a filosofia é para Habermas, assim como fora para Adorno e Marcuse, "um pensamento que não pode ser travado ou imobilizado, apenas corrigido ou orientado por argumentos". 


\section{REFERÊNCIAS}

HABERMAS, Jürgen. Technik und wissenschaft als 'Ideologie'. Frankfurt/M.: Suhrkamp, 1969.

Theorie und praxis: sozialphilosophische studien. 4. ed. rev. aument. Frankfurt/M.: Suhrkamp, 1972.

. Theorie des kommunikativen Handelns. 3. ed. rev. Frankfurt/M.: Suhrkamp, 1985.

. Nachmetaphysisches denken: philosophische aufsätze. 2. ed. Frankfurt/M.:

Suhrkamp, 1988.

. Die einbeziehung des anderen: studien zur politischen Theorie. 2. ed. Frankfurt/M.: Suhrkamp, 1997. 1999.

. Wahrheit und rechtfertigung: plosophische aufsätze. Frankfurt/M.: Suhrkamp,

. Zeit der Übergänge. Frankfurt/M.: Suhrkamp, 2001.

. Zwischen naturalismus und religion: philosophische aufsätze. Frankfurt/M.:

Suhrkamp, 2005.

MAFFESOLI, Michel. A comunicação sem fim (teoria pós-moderna da comunicação). Rev.

FAMECOS, Porto Alegre, v. 10, n.3, p. 13-20, 2003.

MARCUSE, Herbert. Der eindimensionale Mensch. Neuwied: Luchterhand-Verlag, 1967.

WINGERT, Lutz; GÜNTHER, Klaus (eds.). Die Öffentlichkeit der Vernunft und die Vernunft der Öffentlichkeit. Festschrift für Jürgen Habermas. Frankfurt/M.: Suhrkamp, 2001. 